\title{
The Station for Dosing the Substratum into Existing Digesters - PreMix
}

\author{
Slavica Prvulović ${ }^{1)}$ \\ Jasna Tolmac ${ }^{1)}$ \\ Eleonora Desnica ${ }^{1)}$ \\ Milica Josimović ${ }^{1)}$ \\ Ivana Bicok ${ }^{1)}$
}

\begin{abstract}
In this paper the analysis and description of the operation of the Premix station for dosing the substrate into existing digesters whose location is in the system of the device for processing of liquid waste are described.

Apart from the capacity and other entry parameters, the necessary diameter of the pipeline with the length of the section for supplying the devices of the PreMix system is calculated, as it is given in the appropriate tables, the connection of the existing equipment and digesters is presented.

The appropriate dependence of the volume flow, the velocity of circulation and power at constant pressure as well as the dependence of the volume flow, pressure and power at constant velocity of circulation are presented by diagrams.
\end{abstract}

Key words: PreMix system, dosing, substratum, the devices for the processing of liquid waste.

\section{Introduction}

$\mathrm{P}$ REMIX system serves to cut up the broad spectrum of biomass into homogeneous organic suspension, it separates the heavy material and cuts up solids into small pieces before they go into the pump unit. There are compact dimensions in it and it enables an easy connection, so its integration is simple. With the help of only one Remix, it is easy to feed several digesters and enable simple and fast service immediately. The power of PreMix is the mixing of different solids with liquid in order for us to form the homogenous organic suspension which is suitable for decomposition with anaerobic bacteria. For that reason the feeder for solid matter is as suitable for renewable sources as for other entry- materials, no matter if it is food waste, massive crops or organic waste [1-3].

The crucial advantage of PreMix is in its separator for the new matter and for the preparation of biomass, before it comes into the integrated pump with positive extrusion. After the biomass is brought into the filling of solids by worm gear conveyor, the first step is separating of heavy materials. After that, rough particles and fibrous matter too, are cut up into small pieces. This concept does not allow the damage which is made because of pebbles, metal parts and other heavy materials and makes sure that biomass is prepared accurately for decomposition [4-6]. One PreMix can serve a few digesters. Operating power from 20 to $40 \mathrm{kV}$ is enough for (depending on the model) the speed of delivery from 30 to over $100 \mathrm{~m}^{3} / \mathrm{h}$. Thanks to the compact design, a small space of few square meters is enough for the position of PreMix, including a space for service and maintenance $[7,8]$.

One of the characteristics of PreMix is the big simplicity of servicing and maintenance. All the work, including the replacement of parts which are worn out, can be done fast and immediately. According to this, the interruption is reduced to a minimum.

\section{The combination of PreMix with RotaCut pump}

RotaCut combines two main functions: separating and decomposition. While the medium is flowing through RotaCut without interruption, heavy materials, such as stones and metal parts, are separated by gravity, and then, without an effort, they are put off through the hole for cleaning. Apart from that, floating and suspended substances in the medium which are only roughly cut up (fibers, hair, bones, wood, interlaced material) are transported to the sieve for cutting by the flow of liquid and they are cut in small pieces by rotating, self-sharpening cutting edges. In the application it is possible to adjust the unit individually to the means for pumping and the necessary proportion of decreasing the size by choosing the appropriate types of rotors, the sieve for cutting off and separators. In contrast to many systems for comparable power supply, PreMix separates the heavy material while it is still upstream from integrated pump. The optional system for the removal of waste then removes that material during the constant work [8].

Solid and semi-solid entry materials are mixed with the liquid suspension in order for us to get the homogenous suspension. At the same time, rough particles and fibrous matter are cut [10-11].

The well-prepared suspension without disturbing materials and foreign matter comes into the pump. The pipe network enables PreMix to feed power to more digesters without a

\footnotetext{
1) University of Novi Sad, Technical Faculty "Mihajlo Pupin“, Zrenjanin, SERBIA

Correspondence to: Slavica Prvulović, e-mail: prvulovicslavica@yahoo.com
} 
problem, and additional containers can be easily connected later.

In Fig. 1 the appearance of the premix is presented (2 sides), and in Fig.2, the principle of the work of PreMix is given.

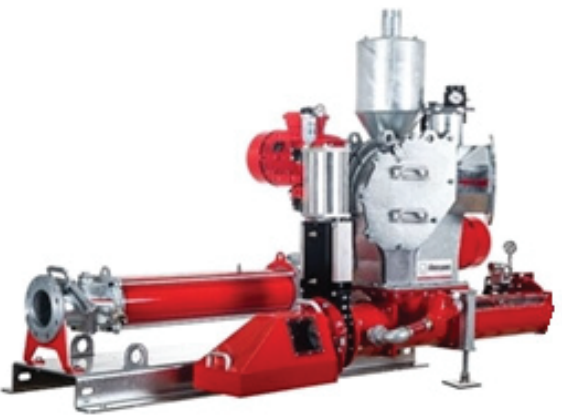

a)

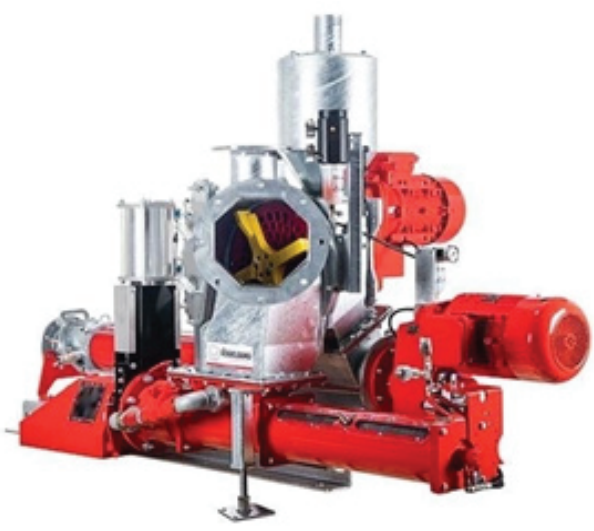

b)

Figure 1. The appearance of the premix

Carrying into the substrata

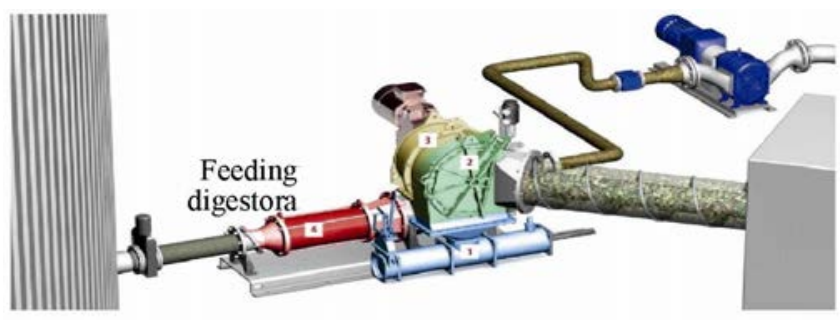

Figure 2. The principle of the work of PreMix

\section{The stations for dosing the silage}

The location of the station for dosing the silage is in the framework of the device for processing of liquid waste, directly next to the previous condensed substance, and opposite to the CHP object and the object of the station for dosing into the digesters 1 and 2 [8].

It is a universal system for accepting the silage from the basket and adding the liquid from the previous condensed substance and for transporting by using the bending pump to the existing pumping station of the device for the processing of liquid waste.

Entry information is acquired by the users depending on the need of their device. On the basis of the given information the algorithm in which the parameters from Table 1 can be brought in can be used. In this way the adequate appliance for adding of the device is made.
Apart from the capacity and other entry parameters, the necessary diameter of the pipeline with the length of the section for supplying the devices of the PreMix system must be calculated, as well as the connecting of the existing equipment (digesters), as it is presented in Table 2 .

Table 1. Entry information

\begin{tabular}{||c|c||}
\hline Content of the dry substance & $15 \%$ \\
\hline Daily amount of the solid substances & $8 \mathrm{t}$ \\
\hline Daily amount of the liquid & $32 \mathrm{~m}^{3}$ \\
\hline Working hours & $1,3 \mathrm{~h}$ \\
\hline Total delivery & $36 \mathrm{~m}^{3}$ \\
\hline The liquid needed for feeding & $25 \mathrm{~m}^{3}$ \\
\hline Differential pressure & $3 \mathrm{bar}$ \\
\hline
\end{tabular}

The tube DN200, Ø200 SDR17 made of polyethylene PEHD is acquired. The thickness of the wall of the tube is $11,9 \mathrm{~mm}$.

The necessary volume flow of the mass is:

$$
V=35 \mathrm{~m}^{3} / \mathrm{h}=0,0097 \mathrm{~m}^{3} / \mathrm{s}
$$

For the acquired tube, the velocity of the circulation is:

$$
V=\frac{V * 4}{d^{2} * \pi}=0,41 \mathrm{~m} / \mathrm{s}
$$

The fall of the pressure at the section whose length is $30 \mathrm{~m}$ is:

$$
\Delta p=\rho * \lambda * * \frac{L}{d} * \frac{V^{2}}{2}=185 \mathrm{~Pa}=0,0018 \text { bar }
$$

\begin{tabular}{|c|c|c|}
\hline \multicolumn{3}{|c|}{ Working conditions } \\
\hline Working medium & & Ferment - Substratum \\
\hline A state of matter & & Liquid \\
\hline Volume flow & $\mathrm{m}^{3} / \mathrm{h}$ & 35,0 \\
\hline The flow of mass & $\mathrm{kg} / \mathrm{h}$ & 34650 \\
\hline Density & $\mathrm{kg} / \mathrm{m}^{3}$ & 990,919 \\
\hline Dynamic viscosity & $10^{-6} \mathrm{~kg} / \mathrm{ms}$ & 1,5 \\
\hline Kinematic viscosity & $10^{-6} \mathrm{~m}^{2} / \mathrm{s}$ & 0,002 \\
\hline \multicolumn{3}{|c|}{ The elements of the pipeline } \\
\hline The mark of the pipeline & & PE HD - Substratum \\
\hline The form of the pipe & & Round pipe \\
\hline Number & & 1 \\
\hline \multirow[t]{2}{*}{$\begin{array}{l}\text { The dimensions of the } \\
\text { pipeline }\end{array}$} & SI & $\begin{array}{l}\text { Diameter of the pipe D in } \mathrm{mm} \text { : } \\
\qquad 200,0\end{array}$ \\
\hline & & $\begin{array}{l}\text { Length of the pipe } \mathrm{L} \text { in } \mathrm{mm} \text { : } \\
\qquad 30,0\end{array}$ \\
\hline \multicolumn{3}{|c|}{ The results of the calculation } \\
\hline Velocity & $\mathrm{m} / \mathrm{s}$ & 0,41 \\
\hline Reynold's number & & $9,346 \mathrm{E}+07$ \\
\hline Type of the circulation & & turbulent \\
\hline Roughness & $\mathrm{mm}$ & 0,03 \\
\hline Abrasion coefficient & & 0,013 \\
\hline Ceta value & & 7,778 \\
\hline The fall of the pressure & bar & 0,0018 \\
\hline
\end{tabular}

Table 2. The results of the calculation of the pipeline substratum

In Fig. 3 the diagram is presented: Volume flow, velocity and power at the constant pressure. 


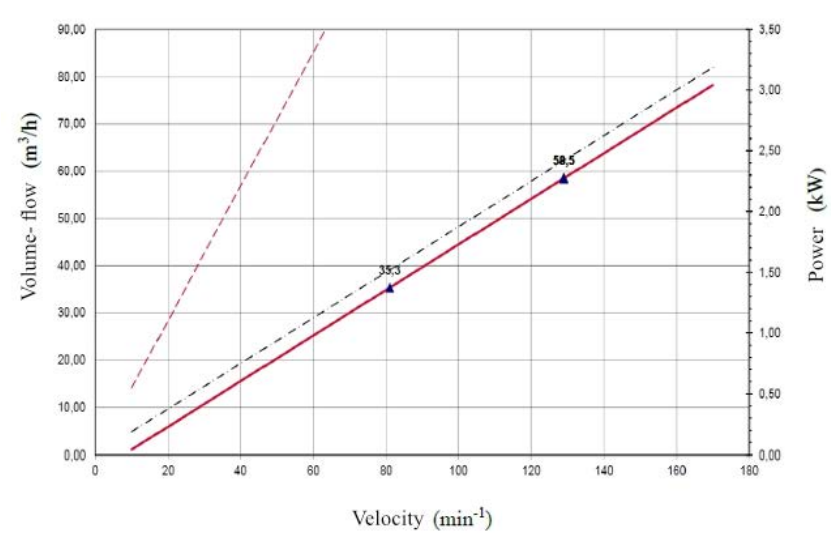

Figure 3. The diagram: Volume- flow, velocity and power at the constant pressure

In Fig.4 the diagram is presented: Volume- flow, pressure and power at the constant velocity

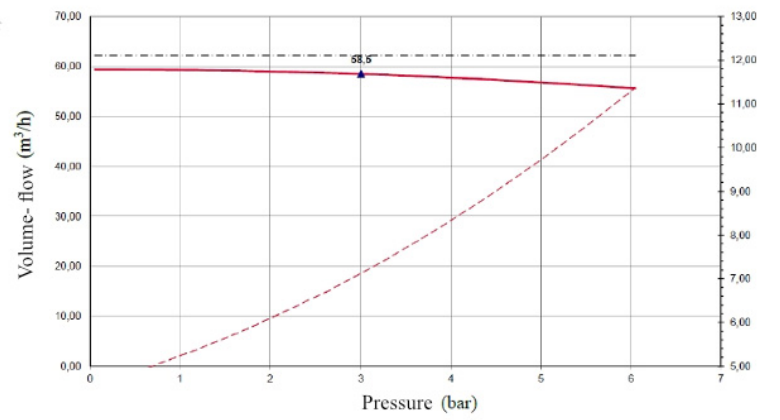

Figure 4. The diagram: Volume- flow, pressure and power at the constant velocity

\section{The choice of the equipment}

On the basis of the position of the existing objects on the terrain, where adding the station for dosing is planned, and according to the given information from calculation, we can choose the position of PreMix.

The position of PreMix is defined according to the direction of the pipe route and the device with which it is being connected. For this adding, Premix with $0^{\circ}$ is chosen, as it is presented in Fig.5 [7].

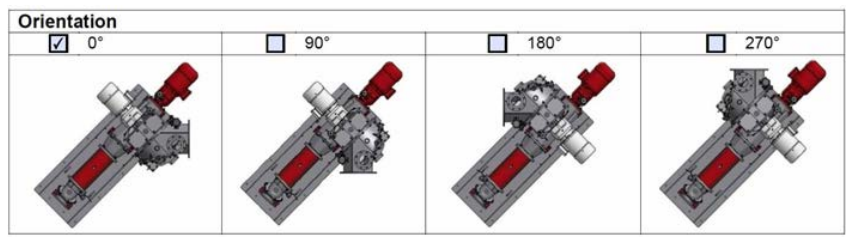

Figure 5. The orientation of the equipment

\section{The technical description with the graphic documentation}

The basket for dosing of the substratum - the silage is made of steel and it is protected by the epoxy coat. The total working volume $V=8 \mathrm{~m}^{3}$, the maximal tonnage of the silage $Q=6,8 \mathrm{t}$. The basket is supplied with the spiral for excluding of the silage and with the spiral for rolling and distributing.

The dimensions of the basket (length $\mathrm{x}$ width $\mathrm{x}$ height): $7,5 \times 2,5 \times 2 \mathrm{~m}$. The basket is supplied with the measuring scales, the giver of the force and in that way daily doses of feeding are defined.

The mass from the basket is inserted into the Pre Mix system by the spiral.

Premix is the universal system for accepting of the silage from the basket and for adding the liquid from previous condensed substance and for the transport by the bending pump towards the existing pump- station of the device for processing of liquid waste.

In the framework of the Pre Mix system Macerator - the device for cutting up the biomass with the separator is integrated.

The pump with the wing- rotors has its function for the transport of the mass from the previous condensed substance towards the bending pump of the Pre Mix system.

The velocity and time of work of dosing the substrate are coordinated with the capacity of dragging the centrifugal pump in the pump- station [8].

Directly before the wing- pump itself, the tube goes from

the ground and goes from polyethylene/ steel and behind the crossing two knife- bars are fitted, one of which is with hand-power and the other is with motor power. The route on the thrust, behind the exit from the PreMix system there are two knife- bars, one of which is with motor power and the other is with hand-power. Behind the valve the stainless steel tube DN150 is led towards the point of landing, which is presented in the graphic documentation, where it crosses

from steel / polyethylene (Ø168,3/ Ø200 SDR17 PN10).

The route is led underground, at the depth of $1,2 \mathrm{~m}$ by the polyethylene tube Ø200 SDR17 PN10.

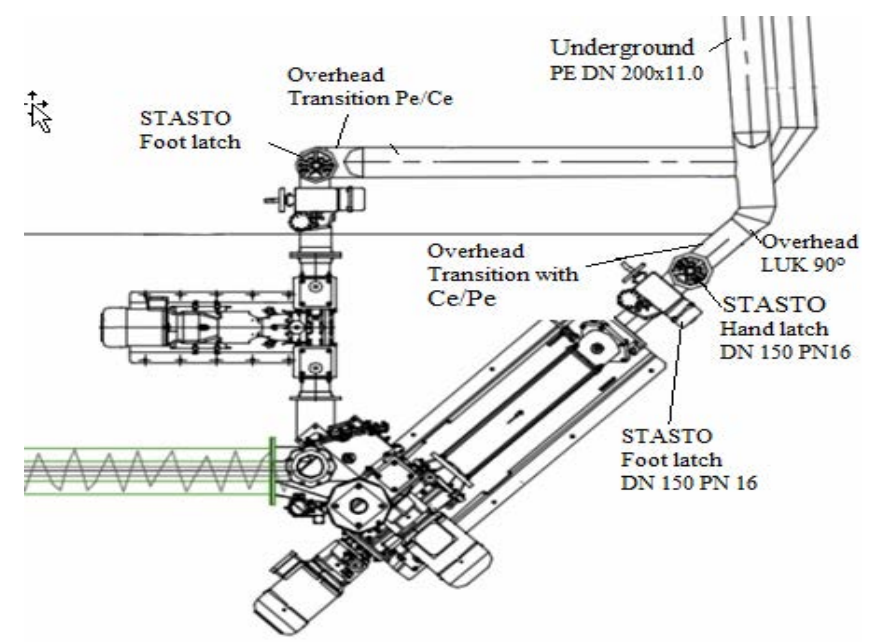

Figure 6. The disposition of the equipment on the plateau

The existing installation is intersected at the point directly next to the existing hole of the previous condensed substance. On the spot of the intersecting a concrete - hole of $2000 \mathrm{x}$ $2000 \mathrm{~mm}$ is formed. The depth of the hole is $3500 \mathrm{~mm}$. The existing pipeline from the previous condensed substance towards the centrifugal pump in the pump- station is intersected in the hole. At the point of intersecting, the steel reduced T - part Ø133/ Ø168,3/ Ø133×5 mm is fitted.

After the $\mathrm{T}$ - part in the direction of the route towards the wing - pump and directly above the $\mathrm{T}$ - part the wedge shaped hand- bar DN 150 PN16, the product: STASTO is fitted. Behind the valve the transitional part steel / polyethylene (Ø168,3/ Ø200 SDR17 PN10) is led. The pipeline is led at the depth of 1,2 $\mathrm{m}$ towards the wing- pump.

\section{Conclusion}

In this paper, the importance of the applicability of PreMix in the framework of the station for dosing the substratum, which is characterized by the unique concept, is presented, as well as the 
operation principle of this system. In the PreMix, the heavy material is separated, and the material with long fibers is cut up into small pieces before entering the pump-unit. It enables the reliable preparation, even of heavy and demanding entrymaterials, by which the pump - unit is protected and its operating life is prolonged significantly [12-16].

In this way, this system represents an ideal concept of the closed circle of devices, which proved as a possibility for decreasing the notices in big systems.

The project assignment with the calculation of the station for dosing was also presented. Apart from the capacity and other entry- parameters, the necessary diameter of the pipeline with the length of the section for supplying the devices of the PreMix system was defined, as well as the connection of the existing equipment and the digester, as it was presented in Table 2. The tube DN200, Ø200 SDR17, made of the polyethylene PEHD, was acquired. The necessary volume flow of the mass, the velocity of circulation of the mass and the fall of the pressure at certain sections, etc., were calculated.

The work of the machine in the combination with the existing equipment on the location, the RotoCut system, where the adding of the device for the processing of liquid waste was made, proved itself as the well- chosen system of feeding and dosing in general [8].

\section{References}

[1] MILANI,M., MONTORSI,L., STEFANI,M.: An integrated approach to energy recovery from biomass and waste: Anaerobic digestiongasification-water treatment, Waste Management and Research, 2014, Vol. 32, No 7, pp. 614-625.

[2] MANGANELLI,B.: Economic feasibility of a biogas cogeneration plant fueled with biogas from animal waste, Advanced Materials Research, 2014, Vol. 864-867, pp. 451-455.

[3] ABUSOGLU,A., ANVARI - MOGHADDAM,A., GUERRERO,J.M.: Producing bio-electricity and bio-heat from urban sewage sludge in Turkey using a two-stage process, 5th International Conference on Power Generation Systems and Renewable Energy Technologies, Istanbul, August 26/27, 2019, pp. 302-306.

[4] METhling,T., ARMBRUST,N., HAITZ,T., (...), RIEDEL,U., SCHEFFKNECHT,G.: Power generation based on biomass by combined fermentation and gasification - A new concept derived from experiments and modelling, Bioresource Technology, 2014, Vol. 169, pp. 510-517.

[5] NAYAL,F.S., MAMMADOV,A., CILIZ,N.: Environmental assessment of energy generation from agricultural and farm waste through anaerobic digestion, Journal of Environmental Management, 2016, Vol. 184, pp. 389-399.

[6] MARKOU,G., BRULÉ,M., BALAFOUTIS,A., (...), GEORGAKAKIS, D., PAPADAKIS,G.: Biogas production from energy crops in Northern Greece: economics of electricity generation associated with heat recovery in a greenhouse, Clean Technologies and Environmental Policy, 2017, Vol.19, No4, pp. 1147-1167.

[7] https://www.vogelsang.info/int/products/solid-matter-feeder/premix/, Data of last access: 12/05/2021.

[8] Project documentation of biogas power plant for wastewater treatment, Zrenjanin, 2019.

[9] LANTZ,M.: The economic performance of combined heat and power from biogas produced from manure in Sweden - A comparison of different CHP technologies, Applied Energy, 2012, Vol. 98, pp. 502-511.

[10] PRAKASH,M., SARKAR,A., SARKAR,J., MONDAL,S.S., CHAKRABORTY, J.P.: Proposal and design of a new biomass based syngas production system integrated with combined heat and power generation, Energy, 2017, Vol. 133, pp. 986-997.

[11] ACHINAS,S., MARTHERUS,D., KROONEMAN,J., EUVERINK,G.J.W.: Preliminary assessment of a biogas-based power plant from organic waste in the North Netherlands, Energies, 2019, Vol.12, No 21, pp. 122-140.

[12] PATANIA,F., GAGLIANO,A., NOCERA,F., GALESI,A.: Feasibility study of biogas in CHP plant for a pig farm, Renewable Energy and Power Quality Journal, 2012, Vol. 1, No 10, pp. 196-201.

[13] MOSAYEBNEZHAD, M., MEHR, A.S., GANDIGLIO, M., LANZINI,A., SANTARELLI,M.:Techno-economic assessment of biogas-fed CHP hybrid systems in a real wastewater treatment plant, Applied Thermal Engineering, 2018, Vol. 129, pp. 1263-1280.

[14] RILEY,D.M., TIAN,J., GÜNGÖR-DEMIRCI,G., (...), RENE VILLALOBOS, J., MILCAREK, R. J.: Techno-economic assessment of chp systems in wastewater treatment plants, Environments - MDPI, 2020, Vol. 7, No 10, pp. 1-32.

[15] KGOMO,J., NGOBENI,A., LENCWE,M., CHOWDHURY,S.P.D.: Design of Combined Heat and Power for Waste Water Treatment Plant, 2019, 10th International Renewable Energy Congress, IREC 2019. 8754637 DOI: 10.1109/IREC.2019.8754637

\section{Stanica za doziranje supstrata u postojeće digestore - PreMix}

